\title{
The effect of dapsone in high and normal dosage on the clinical and cell-mediated immune status of patients with borderline (BT-BL) leprosy
}

\author{
S S LAKSHMANA RAO, ${ }^{*} \mathrm{~J}$ N A STANLEY, $\dagger$ \\ $\mathrm{K}$ U KIRAN, $\dagger$ T DHARMA RAO, * P R RAO* \\ \& J M H PEARSON $† \ddagger$ \\ ${ }^{*}$ Cell and Molecular Biology Laboratory, Department of Zoology, \\ Osmania University, Hyderabad 500 007, India, and †Dhoolpet \\ Leprosy Research Centre, Hyderabad 500 006, India
}

\section{Accepted for publication 8 June 1985}

\begin{abstract}
Summary Twenty-six patients with untreated borderline leprosy, 16 of whom ( R group) had red raised lesions indicating incipient reversal reaction, were allotted randomly to dapsone $1 \mathrm{mg}$ or $4 \mathrm{mg} / \mathrm{kg}$ body weight/day for the initial 2 months of treatment. The $\mathrm{R}$ group patients on high dosage dapsone did not show significantly greater clinical improvement during the trial period. Before treatment, their immune response (leucocyte migration inhibition test) to sonicated (but not whole) $M$. leprae was higher than that of the 10 patients with macular lesions ( $\mathrm{Q}$ group). The response of $\mathrm{Q}$ group patients was unaffected by dapsone treatment, but in $\mathrm{R}$ group patients the response was reduced to $\mathrm{Q}$ group level after 1 month of dapsone treatment (both dosages). This suppression persisted for a week when dapsone was temporarily discontinued.
\end{abstract}

\section{Introduction}

In patients with untreated borderline leprosy, nerve damage develops as a result of intraneural delayed hypersensitivity reactions to antigens of Mycobacterium leprae. ${ }^{2,5}$ Acute episodes are commonly accompanied by the development of red raised skin lesions, and the symptom complex is known as Type 1 lepra reaction (reversal reaction). It is unusual for this reaction to develop with catastrophic suddenness; much more commonly aches and pains and gradually developing erythema and oedema of skin lesions give warning that something is going wrong, and may cause the patient to present himself for treatment. At this stage nerves have usually not been irreversibly damaged, and may still be clinically intact.

‡Correspondence: Dr J M H Pearson, Dhoolpet Leprosy Research Centre, Karwan, Hyderabad 500 006, India. 
There is controversy as to how these patients with incipient reaction should be treated. The use of non-sulphone drugs, or of dapsone in low dosage, has been advocated, but the latter may be harmful, for one study ${ }^{3}$ shows that patients with borderline leprosy receiving initial treatment with dapsone $5 \mathrm{mg}$ daily developed significantly more reaction than did patients starting on $50 \mathrm{mg}$ daily. Certainly there is a need for a simple and safe treatment that will usually prevent incipient reaction progressing to the 'full blown' stage.

The results of the same study ${ }^{3}$ suggest that simply initiating treatment with dapsone at full dosage is good enough management. However, in another study ${ }^{6}$ it has been reported that when Ethiopian patients were treated with dapsone 200 mg daily for 1-2 months there appeared to be exceptionally rapid clinical improvement; aches and pains and red raised skin lesions usually subsided within a few weeks and steroid treatment was very seldom required. Similar results have been seen in Indian patients (Pearson; unpublished observations). The aim of this study was therefore to determine whether any clearcut advantage was obtained by initiating treatment with dapsone at higher than average dosage in patients with borderline leprosy. In addition, because the rapid benefit of dapsone in causing skin lesions to become less inflamed, suggests that it possesses immunological activity, changes in cell-mediated immune responses which could be attributed to the action of dapsone per se were measured, and could be compared with the clinical progress of the patients.

\section{Patients, materials and methods}

\section{CLINICAL STUDIES}

The clinical trial was carried out at Dhoolpet Leprosy Research Centre, Hyderabad. The patients all had clinical borderline (BT or BL) ${ }^{12}$ leprosy. None had received scientific antileprosy treatment during the previous 2 years and none required corticosteroids at the start of the trial.

Initial assessments included clinical examination with body outline charts and palpation for nerve enlargement. Slit skin smears (from 1 or both ear lobes and 24 active looking skin lesions) were performed, as was skin biopsy for histopathological classification. ${ }^{12}$ Tests for nerve function included muscle power tests (VMT) of muscles supplied by the ulnar, median, and lateral popliteal nerves, and tests for protective sensation of the palms and soles. The urine was tested for dapsone (dapsone/creatinine $(\mathrm{D} / \mathrm{C})$ ratio).

The patients could be divided into 2 groups, those with quiescent looking hypopigmented macules ( $\mathrm{Q}$ group) and those in whom some or all of the lesions were raised and erythematous ( $\mathrm{R}$ group). Patients in both groups were randomly allocated to treatment with high (about $4 \mathrm{mg} / \mathrm{kg}$ bodyweight/day) or normal (about $1 \mathrm{mg} / \mathrm{kg} /$ day) dosage of dapsone. 
The trial covered a period of $2 \frac{1}{4}$ months. All patients were treated as outpatients, and were seen at 1,2 and $2 \frac{1}{4}$ months (more frequently if necessary). On each visit the assessments (which could not be done blindly) were repeated, and the patients' clinical progress (particularly changes in the erythema and oedema of skin lesions) graded as improved (mild, moderate, or marked), no change, or worse (mild, moderate or marked). Enquiries were made about possible adverse effects of the treatment noticed by the patient. The urine was tested for dapsone (D/C ratio) at each visit and the skin biopsy repeated at 2 months. Patients were withdrawn from the trial at any time, if it was judged that they required treatment with corticosteroids.

Dapsone was then withheld for a week, and the patients then reassessed. Those on high dosage were transferred to normal dosage, and those with BL leprosy received appropriate multidrug therapy.

\section{IMMUNOLOGICAL STUDIES}

Leucocyte migration inhibition tests (LMIT) were undertaken in the Department of Zoology, Osmania University, Hyderabad, and performed at the times of clinical assessments, that is pre-treatment, 1 month, 2 months, and $2 \frac{1}{4}$ months. The original method of one study ${ }^{15}$ as modified by another ${ }^{10}$ was used. After incubation at $37^{\circ} \mathrm{C}$ for $18 \mathrm{~h}$, the areas of migration were measured with a planimeter. All the tests were run in triplicate and the average value was used to calculate the migratory index (MI) as follows:

$$
\mathrm{MI}=\frac{\text { Average area of migration in the test chamber }}{\text { Average area of migration in the control chamber }} \text {. }
$$

The $M$. leprae antigens were preservative-free armadillo derived preparations (Batch AB51) kindly supplied by Dr R J W Rees (National Institute for Medical Research, London, England). Suspensions of whole bacilli (MLW) or sonicated bacilli (MLS) were used at the concentration (or equivalent concentration) of $2.5 \times 10^{7}$ bacilli $/ \mathrm{ml}$, which was previously shown to be optimal for this batch and this system in our laboratory. ${ }^{10}$ Phytohaemagglutinin (PHA-P) was a 'Difco' product which was found to give optimal responses (without signs of agglutination of leucocytes) at $10 \mu \mathrm{g} / \mathrm{ml}$ concentration in a preliminary dose-response study (at $20 \mu \mathrm{g} / \mathrm{ml}$ agglutination of leucocytes was observed in the migration chambers). All reagents were stored aliquotted at $-20^{\circ} \mathrm{C}$ until used.

Student's $t$-test was used for statistical analysis.

\section{Results}

CLINICAL

Fifty-one patients were entered for the study. However 2 (both R group, 1 high dose, 1 normal dose) had to be withdrawn because they required corticosteroid 
treatment before the end of the study. A further 21 patients either defaulted from the study or attended too irregularly for their immunological results to be analysed. (These drop-outs were somewhat more frequent among the Q group patients, but were not influenced by the dapsone dosage.) The immunological results of 2 patients were incomplete due to technical problems. The results of 26 patients are available for analysis; the clinical classification, grouping, and treatment are shown in Table 1.

The clinical progress of the 26 patients is shown in Table 2. The Q group patients showed very little clinical change; $R$ group patients did better, and there was a tendency for the high dose treated patients to show a greater degree of improvement. This trend applied to both BL and BT cases. However, when initial and final biopsies were compared, no consistent differences could be detected between the high and normal dose treated patients, even in $\mathrm{R}$ group cases. There was little change in the results of nerve function tests during the trial period. Urine tests indicated that most patients were taking their treatment as prescribed.

Table 1. Classification, ${ }^{*}$ clinical features and dapsone dosage of 26 patients with borderline leprosy

\begin{tabular}{ccccc}
\hline & \multicolumn{4}{c}{ Number of patients } \\
\cline { 2 - 5 } $\begin{array}{c}\text { Clinical } \\
\text { classification }\end{array}$ & \multicolumn{2}{c}{ Q group } & \multicolumn{2}{c}{ R group } \\
\cline { 2 - 5 } & $1 \mathrm{mg} / \mathrm{kg} /$ day & $4 \mathrm{mg} / \mathrm{kg} /$ day & $1 \mathrm{mg} / \mathrm{kg} /$ day & $4 \mathrm{mg} / \mathrm{kg} /$ day \\
\hline BL & 1 & 1 & 2 & 5 \\
BT & 4 & 4 & 6 & 3 \\
Total & 5 & 5 & 8 & 8 \\
\hline
\end{tabular}

* The histological classification agreed with the clinical classification except that $3 \mathrm{BL}$ patients were classified histologically as LLs.

Table 2. Clinical progress of 26 trial patients

\begin{tabular}{|c|c|c|c|c|c|c|}
\hline \multirow{3}{*}{$\begin{array}{l}\text { Patient } \\
\text { group }\end{array}$} & \multirow{3}{*}{$\begin{array}{c}\text { Dapsone } \\
\text { dosage }\end{array}$} & \multicolumn{5}{|c|}{ Result of final clinical assessment } \\
\hline & & \multirow[b]{2}{*}{ Worse } & \multirow{2}{*}{$\begin{array}{c}\text { No } \\
\text { change }\end{array}$} & \multicolumn{2}{|c|}{ Improved } & \multirow[b]{2}{*}{ Marked } \\
\hline & & & & Mild & Moderate & \\
\hline \multirow{2}{*}{ Q } & Normal & 0 & 3 & 2 & 0 & 0 \\
\hline & High & 1 & 1 & 3 & 0 & 0 \\
\hline \multirow[b]{2}{*}{$\mathbf{R}$} & Normal & 0 & 0 & 5 & 1 & 2 \\
\hline & High & 0 & 0 & 2 & 3 & 3 \\
\hline
\end{tabular}




\section{IMMUNOLOGICAL}

During dapsone treatment immunological tests were performed at 1 and 2 months. However, there was no consistent pattern of differences between month 1 and month 2 readings; all 'during treatment' results therefore employ the average values of the 2 readings for each patient. Similarly there were few differences between the effects of the two dapsone dosages; the results therefore compare $\mathrm{Q}$ and $\mathrm{R}$ group patients regardless of their dapsone dosage.

The pre-treatment migratory indices to PHA, MLW, and MLS are shown in Table 3; the Q and R groups of patients responded equally to PHA and MLW, but $R$ patients responded more strongly $(0.83 \pm 0.02)$ than $Q$ patients $(1.02 \pm 0.04)$ to MLS $(P<0.001)$. Dapsone treatment had no effect on PHA or MLW responses in either group of patients. However, there was marked suppression of the response to MLS in R group patients but not in Q group (Table 3). The suppression had developed fully within a month of starting dapsone treatment, and was unchanged when dapsone had been discontinued for a week.

Figure 1 shows the percentage increase in migratory index (i.e. the degree of suppression of the immune response to MLS) for each patient in relation to his clinical progress. The suppression was not related either to the dosage of dapsone or to the clinical response of the patient.

\section{Discussion}

\section{CLINICAL FINDINGS}

The results of this study confirm those of Barnetson et al. ${ }^{3}$ that the use of

Table 3. Effect of treatment with dapsone on cell-mediated immune responses of 2 groups of borderline leprosy patients (values given are mean migratory index\pm standard error)

\begin{tabular}{|c|c|c|c|c|}
\hline \multirow[b]{2}{*}{ Mitogen/antigen } & \multicolumn{2}{|c|}{$\begin{array}{l}\text { Quiescent lesion group (Q) } \\
\text { (10 cases) }\end{array}$} & \multicolumn{2}{|c|}{$\begin{array}{c}\text { Incipient reaction group ( } R) \\
\text { (16 cases) }\end{array}$} \\
\hline & $\begin{array}{l}\text { Before } \\
\text { treatment }\end{array}$ & $\begin{array}{l}\text { During } \\
\text { treatment }\end{array}$ & $\begin{array}{l}\text { Before } \\
\text { treatment }\end{array}$ & $\begin{array}{l}\text { During } \\
\text { treatment }\end{array}$ \\
\hline PHA-P & $0 \cdot 58 \pm 0 \cdot 08$ & $0 \cdot 64 \pm 0 \cdot 04$ & $0 \cdot 54 \pm 0.05$ & $0.60 \pm 0.04$ \\
\hline $\begin{array}{l}\text { M. leprae } \\
\text { (whole bacilli) }\end{array}$ & $0.90 \pm 0.04$ & $0.94 \pm 0.03$ & $0.93 \pm 0.04$ & $0.92 \pm 0.03$ \\
\hline $\begin{array}{l}\text { M. leprae } \\
\text { (sonicated) }\end{array}$ & $1 \cdot 20 \pm 0.04$ & $0.97 \pm 0.03$ & $\begin{array}{r}0 \cdot 83 \pm 0 \cdot 02 \\
(P\end{array}$ & $0.99 \pm 0 \cdot 02$ \\
\hline
\end{tabular}

Statistical significance, if any, is given in parenthesis between the mean values. 


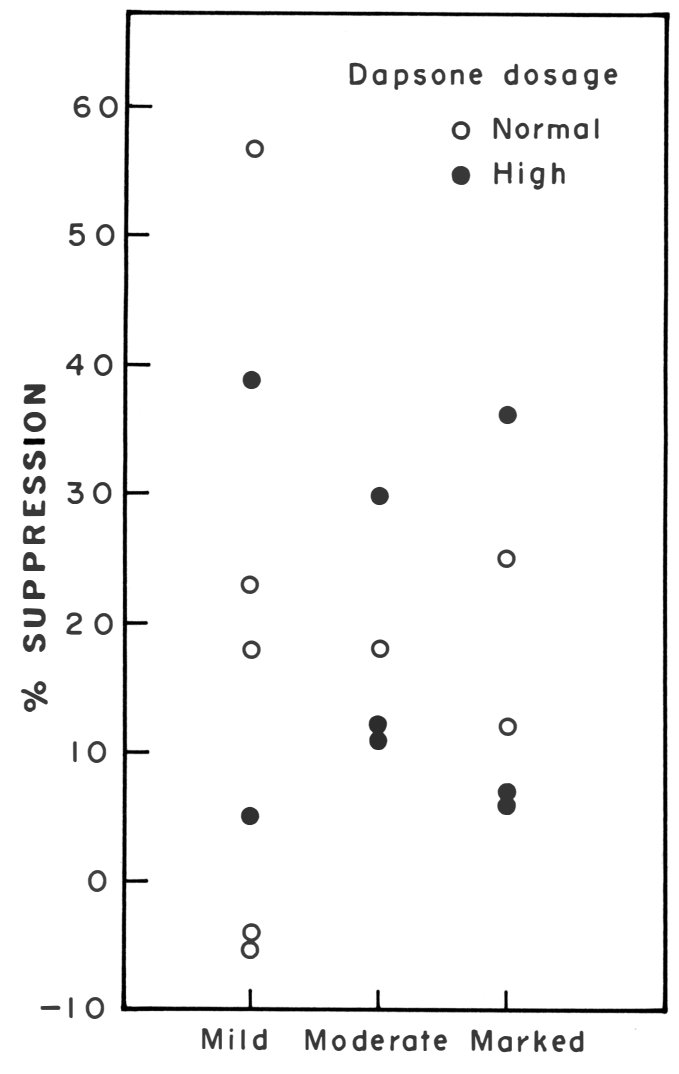

CLINICAL IMPROVEMENT

Figure 1. Percentage suppression of leucocyte migration inhibition to MLS of $16 \mathrm{R}$ group patients according to their clinical improvement during the trial period.

orthodox dosage of dapsone ab initio will usually prevent patients with incipient reaction from developing full blown reaction. We failed to show any clear advantage in using dapsone in high dosage in these patients. Although this was not a very large scale study, this result was quite clear, even though preliminary uncontrolled studies had suggested to us that high dosage might well be much better.

The trial was too short for anti-bacterial action of dapsone to become apparent or for histological regression of the skin lesions to occur. Subsidence of inflammation of the skin lesions was therefore due to altered immune responses. That dapsone has such immunological activity has been suggested by Barnetson ${ }^{3}$ and is supported by studies ${ }^{4,}{ }^{13}$ which showed impaired responses to PHA induced by dapsone in vitro and in vivo respectively. Moreover, in one study ${ }^{17}$ it is reported that there is a reduction in the number of circulating $\mathrm{T}$ lymphocytes in dapsone treated guinea-pigs. 


\section{IMMUNOLOGICAL FINDINGS}

An unexpected dissociation of responses to 'whole bacillary' and 'crude sonicate' $M$. leprae antigens has been demonstrated in the LTT system in patients with borderline (BT-BL) leprosy who developed reactions: ${ }^{2}$ lymphocytes of patients with 'skin reactions' responded strongly to whole $M$. leprae and less strongly to the sonicate, whereas patients with 'nerve reactions' but little skin involvement responded relatively much more strongly to sonicated $M$. leprae. We have also previously reported such a dissociation of responses; MLW responses were more markedly suppressed than MLS responses following lepromin injection in healthy contacts of leprosy patients. ${ }^{11}$ The same system and batches of antigens were employed as in the present study, in which one of the two main findings was also a 'whole/ sonicate' dissociation. MLS but not MLW inhibited leucocyte migration in $\mathrm{R}$ group patients. This suggests that incipient reversal reaction could possibly be a manifestation of delayed hypersensitivity response to antigens that are exposed when $M$. leprae are broken up in vivo. Dissociations of this sort deserve further study using better characterized antigens and systems that can identify specific lymphokines (such as gamma interferon).

Our second main finding was that this inhibition disappeared during dapsone treatment at both high and normal dosage levels. The effect was established within a month and persisted for at least a week after stopping dapsone. Suppressor $\mathrm{T}$ lymphocyte percentages (as estimated by rosetting) ${ }^{8}, 14$ were unchanged throughout the study. The way in which dapsone brought about this effect is unclear, but its absence in Q group patients suggests that dapsone affects some component of the hypersensitivity process present in $\mathrm{R}$ group cases. This, and the absence of suppression of MLW responses in all our patients indicates that the effect is highly specific.

The lack of relationship between clinical improvement and suppression of MLS responses (Figure 1) indicates that additional mechanisms are likely to be involved in the processes which caused the skin lesions of our $\mathrm{R}$ group patients to subside. Indeed, dapsone has a number of activities which could suppress inflammation in skin lesions. It has been shown, for instance, to affect polymorph function, ${ }^{1}$ macrophage activity, ${ }^{7,}{ }^{9}$ and immune complex formation. ${ }^{16}$ The benefits of dapsone for patients with borderline leprosy are evidently not limited to its chemotherapeutic effects, and broader based studies of the immunological activities of dapsone in leprosy patients appear warranted.

\section{Acknowledgments}

We are grateful to the patients who participated in this study, and to Mr Mohd Ismail for skilled technical assistance. TDR acknowledges financial support from the Council of Scientific and Industrial Research, India. Dhoolpet Leprosy 
Research Centre is managed by Victoria Hospital Dichpalli in collaboration with the (British) Medical Research Council and also receives support from the British Leprosy Relief Association (LEPRA).

\section{References}

1 Anderson R, Gatner EMS, Van Rensberg CE, Grabow G, Imkamp FMJH, Kok SH, Van Rensburg AJ. Invitro and in vivo eff ects of dapsone on neutrophil and lymphocyte functions in normal individuals and patients with lepromatous leprosy. Antimicrobag Chemother, 1981; 19: 495.

2 Barnetson R StC, Bjune G, Pearson JMH, Kronvall G. Antigenic heterogeneity in patients with reactions in borderline leprosy. Br Med J, 1975; 4: 435.

${ }^{3}$ Barnetson R StC, Pearson JMH, Rees RJW. Evidence for prevention of borderline leprosy reactions by dapsone. Lancet, 1976; ii: 1171 .

${ }^{4}$ Beiguelman B, Pisani RCB. Effect of DDS on phytohemagglutinin induced lymphocyte transformation. Int J Lepr, 1974; 42: 412.

5 Godal T, Myrvang B, Samuel DR, Ross WF, Lof gren M. Mechanism of 'reactions' in borderline tuberculoid (BT) leprosy. Acta Path Microbiol Scand, Sect. A Suppl, 1973; 236: 45.

${ }^{6}$ Haile GS, Pearson JMH. The use of dapsone in high dosage to prevent reversal reactions in borderline leprosy. Paper presented at the 13th Annual Conference of the Ethiopian Medical Association, 1977.

${ }^{7}$ Lewis AJ, Gemmeli DK, Stimson WH. The anti-inflammatory profile of dapsone in animal models of inflammation. Agents and actions 8/6 (1978). Birkhauser Verlag, Basel, Switzerland, 578.

8 Moretta L, Ferrarini M, Mingari MC, Moretta A, Webb SR. Sub-populations of human T cells identified by receptors for immunoglobulins and mitogen responsiveness. $J$ Immunol, 1976; $117 ; 2171$.

9 Mier PD, Van Hurk JJMA. Inhibition of lysosomal enzymes by dapsone. Br J Derm, 1975, 93: 471.

${ }^{10}$ Rao SSL, Rao PR. Immunological status of maculoanaesthetic leprosy; leukocyte migration inhibition test as a measure of cell-mediated immune response. Lepr India, 1981; 53: 340.

11 Rao SSL, Stanley JNA, Pearson JMH. Suppression of Mycobacterium leprae-induced leucocyte migration inhibition following lepromin injection in healthy contacts of leprosy-Preliminary observations. Lepr Rev, 1985; 56: 291-295.

12 Ridley DS, Jopling WH. Classification of leprosy according to immunity. A five-group system. Int J Lepr, 1966; 34: 255.

${ }^{13}$ Sengupta U, Ghei SK, Venkatesan K, Bharadwaj VP. In vivo effects of DDS on phytohemagglutinin (PHA)-induced lymphocyte transformation cultures in normal healthy volunteers. Int $J$ Lepr, 1979; 47: 167.

14 Singh S, Nath I. Identification of $\mathrm{T}$ lymphocytes with $\mathrm{Fc}$ receptors for Ig G in normal Indians. Ind J Med Res, 1980; 72; 385.

15 Soborg M, Bendixen G. Human lymphocyte migration as a parameter of hypersensitivity. Acta Med Scand, 1967; 181: 247.

16 Thomson DM, Souhani R. Suppression of the Arthus reaction in the guinea pig by dapsone. Proc RSM, 1975; 68: 273.

17 Tsutsumi S, Gidoh M. Fundamental studies on the immunomodulative control of leprosy by pharmacotherapeutic means. Paper presented at the 17th US-Japan Joint Leprosy Conference, Sendai-Shi, Japan, July 1982. Int J Lepr, 1982; 50: 589. 